\title{
IMPLEMENTAÇÃO DE UMA REDE NEURAL MLP APLICADA À IDENTIFICAÇÃO DE SINAIS DE DESCARGAS PARCIAIS
}

\author{
Euler C. T. De Macedo, Juan M. M. Villanueva*, Edson G. da Costa, Raimundo C. S. \\ Freire, José M. R. De Souza Neto ${ }^{\dagger}$, Ian A. Glover
}

${ }^{*}$ Departamento de Engenharia Elétrica

Centro de Energias Alternativas e Renováveis, Universidade Federal da Paraíba João Pessoa, PB, Brasil

$\dagger$ Departamento de Engenharia Elétrica

Centro de Engenharia Elétrica e Informática, Universidade Federal de Campina Grande Campina Grande, PB, Brasil

¥Department of Engineering \& Technology

School of Computing \& Engineering, University of Huddersfield

Queensgate, Huddersfield, United Kingdom

Emails: euler@cear.ufpb.br, jmauricio@cear.ufpb.br, edson@dee.ufcg.edu.br, freire@dee.ufcg.edu.br, jose.neto@ee.ufcg.edu.br, i.a.glover@hud.ac.uk

\begin{abstract}
Partial discharges measurements are an important tool for the determination of the degradation level of high voltage apparatus. If partial discharge is found in insulating systems then it is important to identify its character, i.e. internal discharge, surface discharge, corona etc. For many years partial discharge recognition was performed by observation, and (human) expert interpretation, of partial discharges patterns on the power frequency ellipse displayed using an oscilloscope. The aim of this paper is present a methodology for the automatic (aid computer) classification partial discharges signals based on the employment of two optimized neural networks topologies.
\end{abstract}

Keywords - Partial discharge, Insulation defects classification, statistical operators, neural networks.

Resumo - Medições de Descargas Parciais são uma importante ferramenta para a determinação do nível de degradação dos isolamentos de equipamentos de alta-tensão. Durante muitos anos, a avaliação dos padrões obtidos a partir de sinais de descargas parciais era feita de forma visual, por meio da representação gráfica dos sinais de corrente e tensão utilizando osciloscópios. O emprego de computadores e técnicas de inteligência artificial em medições de descargas parciais permite o reconhecimento automático de padrões obtidos a partir das medições de descargas parciais tanto em campo quanto em laboratório. Este trabalho trata sobre a identificação automática de padrões de descargas parciais utilizando a aplicação de operadores estatísticos como parâmetros de entrada de uma rede neural artificial otimizada, a qual permite a determinação da melhor topologia de redes neurais artificiais aplicada a identificação de descargas parciais.

Keywords - Descargas Parciais, identificação de padrões, monitoramento em tempo real, operadores estatísticos.

\section{Introdução}

Dentre diversas formas de se realizar o monitoramento de sistemas de isolamentos elétricos, a medição de descargas parciais é considerada como uma das mais consolidadas soluções, e que permite a detecção prévia de possíveis defeitos nos isolamentos que são partes constítuintes de equipamentos de alta tensão.

As descargas parciais se caracterizam por pulsos de corrente de alta frequência que ocorrem no interior dos equipamentos elétricos de alta tensão, e são originadas pelo processo de ionização do meio gasoso submetido a um campo elétrico elevado (Nattrass, 1988). Elas são fontes potenciais de defeitos nos isolamentos elétricos. Inicialmente, o fenômeno ocorre no isolamento elétrico de forma parcial e existe a tendência, devido à fragilização do meio isolante, de se tornar total, o que causaria um curto circuito entre as partes energizadas e o terra, danificando assim, o equipamento elétrico.
Portanto, os níveis de ocorrência de descargas parciais devem ser acompanhados periodicamente durante a vida útil do equipamento (Carvalho, 2009).

Graças ao desenvolvimento de outras áreas da engenharia elétrica, os sistemas de monitoramento de isolamentos baseados na medição de descargas parciais vem se tornando cada vez mais robustos e economicamente viáveis.

Adicionalmente, com a elaboração de normas internacionais específicas sobre descargas parciais, tais como a IEC 60270 (IEC 60270, 2000), houve o estabelecimento de procedimentos experimentais bem definidos, com explicações detalhadas de como se proceder o monitoramento de descargas parciais em equipamentos de alta tensão.

Geralmente, a maior dificuldade em realizar medições de descargas parciais é a presença de ruídos existentes no ambiente da medição. Dependendo do ambiente de medição ou dos níveis de descargas parciais a serem medidas, o nível de 
ruído do ambiente pode ser superior ao valor da descarga parcial que se deseja avaliar. Portanto, faz-se necessário utilizar sistemas de filtragem, sofisticados ou não, para detectar e medir os sinais de descargas parciais corretamente (de Macedo et al., 2012).

Uma vez feita à atenuação e/ou supressão das interferências do ambiente de medição, existe a possibilidade de correlacionar o sinal de descarga parcial com o tipo de falha do isolamento de equipamentos de potência que causam a descarga, isto é o local, tipo ou configuração da falha, etc. Esta correlação (classificação) é feita a partir do conhecimento de atributos extraíveis dos sinais de descarga parcial e sua correlação com o tipo de falha existente.

Geralmente, a classificação é realizada pela criação de uma assinatura correspondente a cada tipo de falha existente no isolamento. A geração da assinatura pode ser feita dentre outras formas utilizando operadores estatísticos. O cálculo e análise dos operadores estatísticos permitem avaliar e descrever as principais características dos sinais de descarga parcial, principalmente quando os operadores são analisados de forma conjunta.

Após a geração da assinatura correspondente a cada tipo de defeito, é possível automatizar a identificação das fontes de descargas parciais por meio de técnicas de inteligência artificial. Como exemplo destas técnicas podem-se citar: a lógica Fuzzy, redes neurais artificiais (RNA), máquinas de aprendizagem, dentre outras.

O objetivo deste trabalho é apresentar o desenvolvimento de uma rede neural do tipo Perceptron Multicamadas (MLP) baseada no algoritmo backpropagation, a qual foi organizada para que fosse utilizado o menor número possível de neurônios em cada camada oculta para uma taxa de acerto pré-estabelecida, aumentando assim, o desempenho da identificação e consequentemente a redução dos requisitos computacionais do sistema.

\section{Fundamentação Teórica e Metodologia}

De forma simplificada, o procedimento geral para desenvolver um sistema de identificação de falhas de isolamentos elétricos, a partir da medição de descargas parciais, pode ser descrito da seguinte maneira:

1. Teste de corpos de prova com falhas previamente conhecidas, com o objetivo de se obter um banco de dados de referência;

2. Filtragem dos sinais medidos em laboratório, de forma a atenuar os sinais espúrios;

3. Realização do processamento estatístico dos bancos de dados gerados, com o objetivo de determinar os melhores identificadores para cada tipo de defeito;
4. Implementação de classificadores de dados adequados, que podem ser baseados em técnicas de inteligência artificial e/ou por meio da utilização de parâmetros estatísticos.

As etapas 1 e 2 serão apresentadas sucintamente a seguir, enquanto que as etapas 3 e 4 são o foco deste trabalho. Maiores informações sobre as etapas 1 e 2 podem ser obtidas em (de Souza Neto et al., 2012) e (de Macedo et al., 2012).

\subsection{Arranjo Experimental para Geração de Descargas Parciais}

De acordo com a norma (IEC 60270, 2000), as descargas parciais podem ser classificadas em três classes, dependendo da sua localização, sendo elas: descargas internas, corona e de superfície.

As descargas internas ocorrem em uma ou mais rupturas (cavidades) no interior de um material dielétrico isolante. As descargas de superfície ocorrem na superfície do dielétrico, principalmente em buchas, terminações de cabos ou em enrolamentos de geradores. As descargas corona ocorrem em meios gasosos quando há uma intensificação do campo elétrico nas proximidades de um eletrodo, ou seja, quando o gradiente elétrico excede um determinado limiar.(Tanaka and Greenwood, 1983).

Com o intuito de emular a ocorrência de descargas parciais internas, adotou-se uma configuração de eletrodos do tipo plano-plano, com dielétrico. Para isto, desenvolveram-se diferentes tipos de corpo de prova, utilizando placas circulares de fenolite, esse tipo de material apresenta alta rigidez dielétrica (ex. $50 \mathrm{kv} / \mathrm{mm}$ ), bem similar aos isolamentos usados nos equipamentos de alta tensão.

Cada corpo de prova é composto por uma sobreposição de placas de fenolite com espessura de 1,6 mm, as placas foram coladas entre si, com uma resina epóxi. A colagem das placas fez com que não houvesse, além de ar, outro componente com características dielétricas desconhecidas dentro do corpo de prova. Algumas das placas foram perfuradas de modo a inserir uma cavidade no dielétrico, o que permite observar o comportamento das falhas na geração de pulsos característicos de descargas parciais. As falhas do dielétrico foram projetadas com dois diferentes diâmetros, $1 \mathrm{~mm}$ e $2 \mathrm{~mm}$, dispostos de modo diferenciado em cada corpo de prova (de Souza Neto et al., 2012).

Na Tabela 1 é apresentado um diagrama ilustrativo dos corpos de prova (cavidades) desenvolvidos utilizando discos de Fenolite, além de apresentar informações como: diâmetro da cavidade, configuração da falha, ou seja, a quantidade e posição geométrica em relação às placas de fenolite. Observando-se na coluna referente à configuração da falha (coluna 3), as regiões 
sombreadas correspondem às cavidades criadas, as demais correspondem ao dielétrico de fenolite sem falhas.

Tabela 1: Configurações de defeitos usados para a geração de descargas parciais.

\begin{tabular}{|c|c|c|}
\hline Defeito & Diâmetro da cavidade $(\mathrm{mm})$ & Configuração da falha \\
\hline 1 & 2 & \\
\hline 2 & 1 & \\
\hline 3 & 2 & \\
\hline 4 & 1 & \\
\hline 5 & 2 & \\
\hline 6 & 1 & \\
\hline 7 & 2 & \\
\hline 8 & 1 & \\
\hline 9 & 2 & \\
\hline 10 & 1 & \\
\hline
\end{tabular}

Para a conexão dos corpos de prova à fonte de alta tensão, foi utilizada uma estrutura geradora de descargas parciais conforme apresentado em de Souza Neto et al. (2012). O arranjo de medição e a fotografia da célula que permite a geração de descargas parciais são apresentados nas Figuras 1 e 2 .

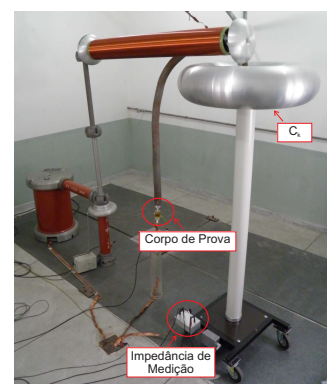

Figura 1: Arranjo de medição de descargas parciais em laboratório.

Para se realizar a medição dos sinais de descargas parciais utilizou-se o sistema comercial LDS-6, fabricado pela Doble Lemke. O sistema possui dois canais independentes para a aquisição de sinais de descargas parciais.

\subsection{Operadores Estatisticos}

Após a aquisição e filtragem dos sinais de descargas parciais, realizou-se a determinação de alguns

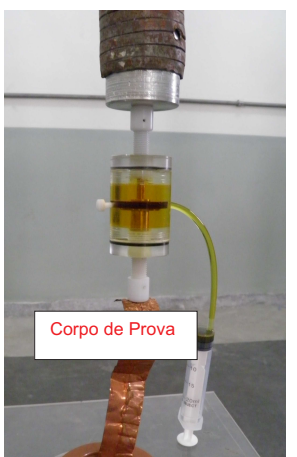

Figura 2: Fotografia da célula geradora de descargas parciais.

dos principais operadores estatísticos empregados na bibliografia com o objetivo de obter uma assinatura característica para cada tipo de defeito sob estudo.

De posse de algumas ou todas essas informações é possível se identificar os tipos de falhas existentes no isolamento, as quais provocam a ocorrência de descargas parciais em equipamentos de potência.

A seguir, apresenta-se uma descrição sucinta sobre os operadores estatísticos usados neste trabalho para a classificação de sinais de descargas parciais:

- Valor de pico (Max): corresponde ao valor máximo das descargas obtidas para os dois semi-ciclos;

- Média (Mean): é a média aritmética dos pulsos de descargas parciais para cada semiciclo;

- Desvio padrão $(S t d)$ : foram calculados o desvio padrão para cada semi-ciclo das distribuições;

- Assimetria (Skewness - Sk): é um indicador para a assimetria de uma distribuição com relação à distribuição normal;

- Curtose (Kurtosis - Ku): é uma medida de dispersão que caracteriza o pico ou "achatamento"da curva da função de distribuição de probabilidadeem função da distribuição normal.

Considerando que a ocorrência das descargas parciais se dá em ambos os semi-ciclos da tensão aplicada, o cálculo dos operadores estatísticos apresentados devem ser calculados separadamente para cada semi-ciclo.

A seguir é feita uma apresentação sucinta acerca de um dos classificadores de dados mais utilizados na atualidade: As Redes Neurais Artificiais. 


\subsection{Redes Neurais Artificiais}

Redes neurais artificiais (RNA) podem ser definidas como sendo uma tecnologia baseada em arquiteturas biológicas de neurônios, que foi especialmente desenvolvida para realizarem trabalhos computacionais. As RNA possuem propriedades particulares tais como a habilidade de adaptar-se e aprender, generalizar, agrupar ou organizar dados. As operações são baseadas em processamento paralelo. Esse tipo de ferramenta computacional é particularmente apropriadas em tarefas de reconhecimento de padrões e classificação, otimização e agrupamento de informações (data clustering) (Haykin, 1997).

Dentre as diversas arquiteturas de RNA, destacam-se como as mais difundidas as redes Perceptron de Múltiplas Camadas (MLP - Multilayer Perceptron). Durante o treinamento, cada resultado apresentado na camada de saída da RNA é confrontado com o resultado esperado. Esta operação é realizada por meio da Função Energia de Erro, definida como o erro médio quadrático entre a saída produzida pela rede e a desejada:

$$
\varepsilon(n)=\frac{1}{2} \sum_{j \in B}\left[d_{j}(n)-y_{j}(n)\right]^{2},
$$

em que, $B$ representa o conjunto de neurônios da camada de saída; $d_{j}(n)$ é a saída desejada do neurônio de saída $j$, para o padrão $n$ do conjunto de treinamento; $y_{j}(n)$ é a saída calculada do neurônio de saída $j$, para o padrão $n$ do conjunto de treinamento. Maiores informações acerca da teoria de redes neurais artificiais podem ser obtidos em (Haykin, 1997).

\section{Construção da Base de Dados}

Os sinais de descargas parciais foram adquiridos utilizando o sistema comercial LDS-6, o qual é baseado no método elétrico de medição apresentado na norma IEC 60270.

Para a criação do banco de dados foram realizadas 10 medições consecutivas durante 20 segundos para cada tipo de defeito (Tabela 1), com a aplicação de quatro níveis de tensão; 15 , 20, 25 e $30 \mathrm{kV}$.

Após a aquisição dos sinais foi realizado um pré-processamento do banco de dados original. Para cada defeito foram gerados três novos arquivos com a informação da ocorrência das descargas parciais para intervalos de tempo correspondentes a 100, 500 e 1000 períodos da tensão aplicada.

Para cada sinal resultante, foram gerados histogramas contendo a distribuição estatística da magnitude dos pulsos com relação a fase da tensão aplicada, representada por $H_{q}(\varphi)$, e em seguida foi calculada a correlação cruzada (CC) entre as distribuições resultantes para cada tipo de defeito. $\mathrm{Na}$ sequência, realizou-se o cálculo da CC entre todas as possíveis combinações das distribuições calculadas e verificou-se quais os sinais para cada medição apresentavam o módulo da CC superior a 0,1 . O valor 0,1 foi escolhido como sendo o valor mínimo de relacionamento linear (similaridade) entre dois sinais de descargas parciais.

Dos sinais medidos, verificou-se que apenas 779 de um total de 1200 eram válidos, ou seja, possuiam $C C \geq 0,1$ entre si.

Em seguida, para cada padrão válido resultante foram calculados os operadores estatísticos apresentados na Seção 2.2. Os resultados obtidos, além da tensão aplicada ao corpo de prova, foram utilizados como entrada de uma RNA multicamada do tipo perceptron backpropagation.

Foram implementadas duas topologias de RNA. Inicialmente adotou-se uma RNA composta por uma camada oculta e avaliou-se de forma iterativa a quantidade de neurônios necessários para que a taxa de acerto fosse igual ou superior a 95\%. Caso esse valor de taxa de acerto não fosse obtido com a utilização de no máximo 40 neurônios na $1^{a}$ camada, uma nova camada seria adicionada automaticamente à RNA. Para a topologia com 2 camadas, o número máximo de neurônios artificiais também foi limitado a 40 . A representação gráfica da RNA implementada é apresentada na Figura 3. Em ambas as topologias de RNA adotou-se uma codificação de quatro bits na saída para rotular cada corpo de prova apresentado na Tabela 1.

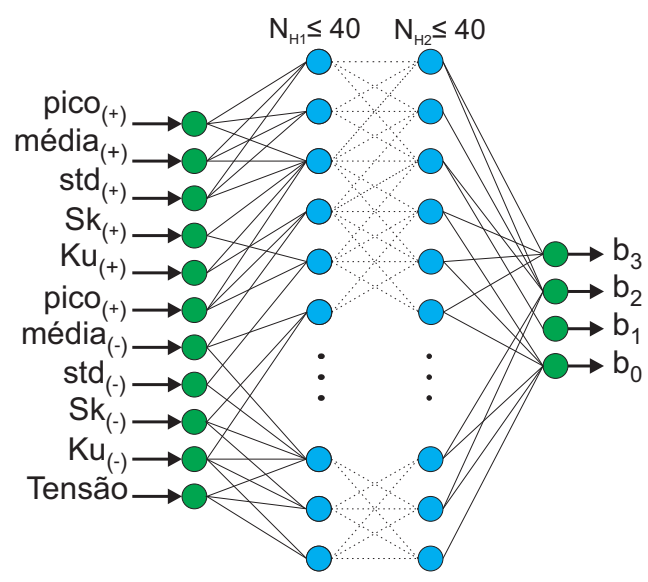

Figura 3: Representação gráfica das RNA implementadas.

Do banco de dados validados, foram escolhidos aleatoriamente, $70 \%$ dos sinais de descargas parciais para o processo de treinamento, $P_{\text {treino }}$ e os $30 \%$ restantes para o processo de teste e verificação, $P_{\text {teste }}$.

O fluxograma de funcionamento da RNA de apenas 1 camada oculta é apresentado na Figura 4.

A RNA é inicializada com os neurônios da 


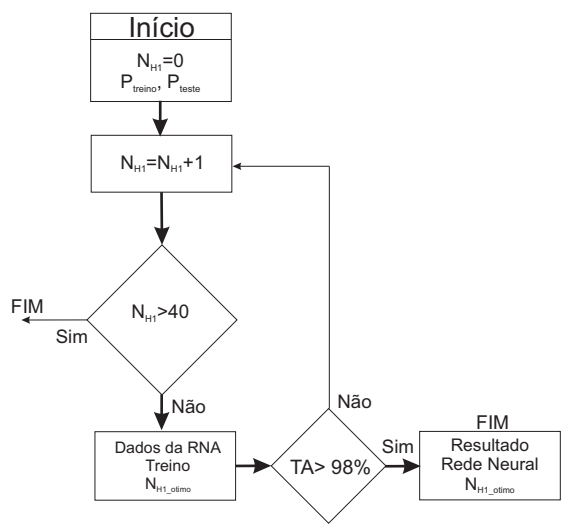

Figura 4: Fluxograma RNA otimizada com 1 camada oculta.

primeira camada iguais a zero, $\left(N_{H 1}=0\right)$, neste momento também são inseridas as informações acerca do banco de dados de treino e teste, $\left(P_{\text {treino }}\right.$ e $\left.P_{\text {teste }}\right)$. Na sequência, há um incremento no número de neurônios da $1^{\mathrm{a}}$ camada oculta $\left(N_{H 1}=N_{H 1}+1\right)$ e realiza-se o teste no número de neurônios usados até o momento, que em nossa aplicação foi limitado em 40. Caso essa condição não seja satisfeita, ocorre a continuidade do processo, ou seja, a RNA é treinada e verificase se a taxa de acerto é superior a 95\%, caso essa condição seja satisfeita, apresenta-se o resultado otimizado da RNA (número de neurônios da $1^{\mathrm{a}}$ camada) caso contrário, ocorre um novo incremento do número de neurônios da camada oculta sob análise, e o processo é reiniciado. Um processo similar foi adotado, agora considerando uma RNA com duas camadas ocultas. Neste caso todas as possíveis combinações para um número máximo de 40 neurônios em cada camada foram avaliadas. O fluxograma do processo iterativo de identificação da RNA com duas camadas ocultas é apresentado na Figura 5.

O processo iterativo de identificação dos defeitos por meio da RNA com duas camadas ocultas é feito seguindo a mesma metodologia da RNA de uma única camada. De forma similar ao fluxograma apresentado na Figura 4. Todas as possíveis combinações de neurônios da primeira e segunda camadas são avaliadas até que a taxa de acerto de identificação fosse superior a $95 \%$.

Para o processo de treinamento supervisionado empregou-se o ambiente computacional MATLAB, que permite implementar a rede neural artificial com a codificação entrada/saída proposta de forma simplificada. Alguns resultados obtidos são apresentados a seguir.

\section{Resultados}

Com o cálculo dos operadores estatísticos apresentados na Seção 2.2 foi possível verificar que cada tipo de defeito, possui características estatísticas

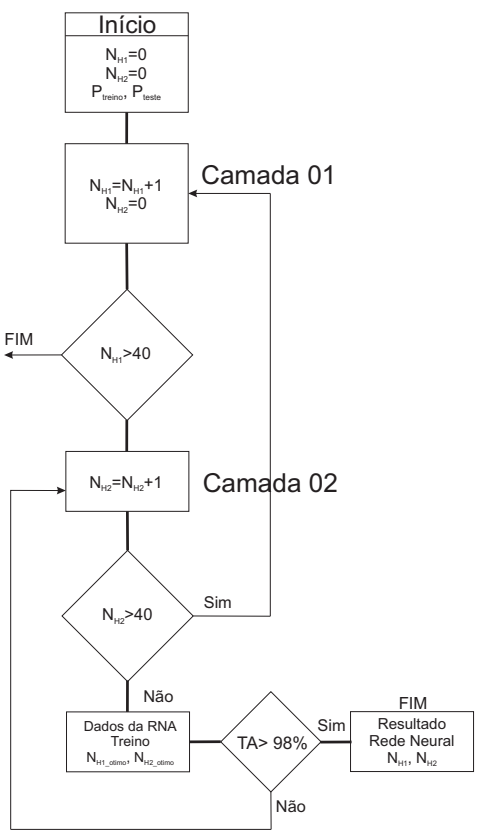

Figura 5: Fluxograma RNA otimizada com 2 camadas ocultas.

bem definidas, o que é útil para identificar cada tipo de defeito em isolamentos sob estudo.

Os resultados obtidos na classificação estatística foram usados na entrada de duas RNA, uma contendo apenas uma única camada oculta e outra com duas camadas ocultas. Para cada camada oculta o número máximo de neurônios artificiais foi previamente limitado em 40. Empregou-se uma codificação de 4 bits na saída da RNA.

Foram realizadas 10 simulações para cada topologia de RNA. Os resultados obtidos foram diferentes para cada instante de simulação, porém é possível se obter uma métrica estatística do processo de treinamento e identificação. Os resultados obtidos são apresentados nas Tabelas 2 e 3 .

Tabela 2: Resultados obtidos para a topologia de RNA com 1 camada oculta.

\begin{tabular}{c|c|c}
\hline \hline Simulação & $N_{\text {H1-otimo }}$ & Taxa de Acerto (\%) \\
\hline \hline 1 & 14 & 79,10 \\
\hline 2 & 13 & 79,90 \\
\hline 3 & 18 & 78,20 \\
\hline 4 & 22 & 73,20 \\
\hline 5 & 22 & 79,1 \\
\hline 6 & 28 & 85,80 \\
\hline 7 & 34 & 81,20 \\
\hline 8 & 30 & 80,30 \\
\hline 9 & 20 & 82,00 \\
\hline 10 & 21 & 81,20 \\
\hline \hline Média & $\approx 21$ & 79,97
\end{tabular}

O desempenho da RNA com 1 camada oculta é representado graficamente com auxilio da Matriz de Confusão apresentada na Figura 6.

Pode-se verificar que com a inserção da segunda camada possibilitou um aumento significa- 


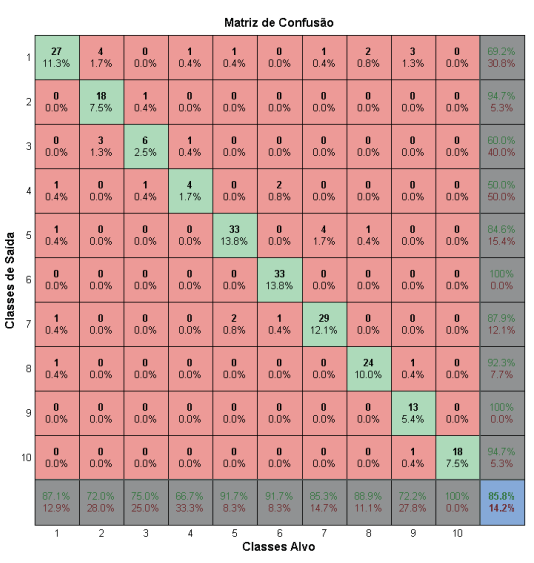

Figura 6: Matriz de Confusão RNA com 1 Camada Oculta.

Tabela 3: Resultados obtidos para a topologia de RNA com 2 camadas ocultas.

\begin{tabular}{c|c|c|c}
\hline \hline Simulação & $N_{\text {H1-otimo }}$ & $N_{\text {H2-otimo }}$ & Taxa de Acerto (\%) \\
\hline \hline 1 & 12 & 25 & 87,90 \\
\hline 2 & 11 & 14 & 90,40 \\
\hline 3 & 17 & 28 & 89,10 \\
\hline 4 & 22 & 34 & 92,10 \\
\hline 5 & 12 & 26 & 87,40 \\
\hline 6 & 37 & 14 & 88,70 \\
\hline 7 & 22 & 31 & 87,40 \\
\hline 8 & 11 & 35 & 88,30 \\
\hline 9 & 40 & 13 & 90,30 \\
\hline 10 & 26 & 34 & 87,50 \\
\hline \hline Média & 21 & $\approx 25$ & 88,91 \\
\hline
\end{tabular}

tivo na taxa de acerto das RNA implementadas.

De forma similar, apresenta-se na Figura 7 a representação gráfica da matriz de confusão da topologia de RNA com duas camadas ocultas que apresentou a maior taxa de acerto.

\section{Conclusões}

Neste trabalho foram apresentados resultados obtidos a partir da classificação estatística e identificação de padrões de sinais de descargas parciais.

Foram implementadas duas topologias de RNA, uma contendo apenas uma camada oculta e outra contendo duas camadas ocultas. O desempenho das RNA para esse tipo de identificação de padrões foi satisfatório, e a taxa de acerto da identificação apresentou um aumento significativo com o aumento da segunda camada oculta.

Outra característica importante, é que verificou-se que o número máximo de 40 neurônios não é o mais apropriado para este tipo de aplicação, haja visto que na primeira topologia, o número máximo de neurônios foi de aproximadamente 21 e na segunda topologia foram de 21 e 26, o que permite a redução do tempo computacional.

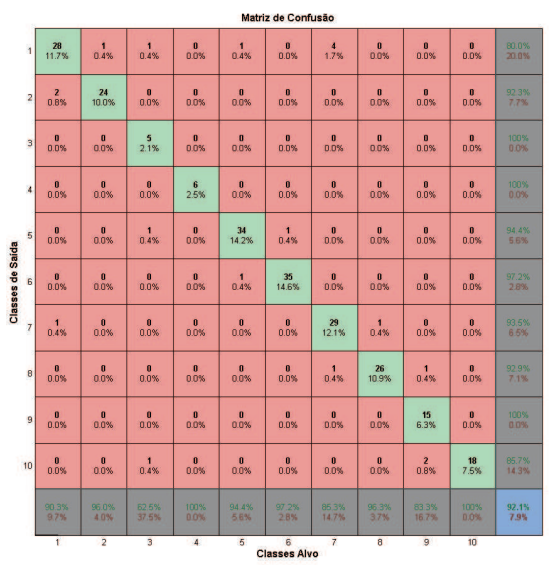

Figura 7: Matriz de Confusão RNA com 2 Camadas Ocultas.

\section{Agradecimentos}

Os autores agradecem ao $\mathrm{CNPq}$ e INCT NAMITEC pelo suporte financeiro deste trabalho.

\section{Referências}

Carvalho, A. (2009). Medições de descargas parciais no campo - aspectos praticos em transformadores de potência, XIII Eriac Décimo Tercer Encuentro Regional Iberoamericano de Cigré .

de Macedo, E. C. T., Araujo, D. B., da Costa, E. G., Freire, R. C. S., Lopes, W. T. A., Torres, I. S. M., de Souza Neto, J. M. R., Bhatti, S. A. and Glover, I. A. (2012). Wavelet transform processing applied to partial discharge evaluation, Journal of Physics: Conference Series 364(1): 012054. DOI: 10.1088/1742-6596/364/1/012054

de Souza Neto, J., de Macedo, E., Cavalcanti, T., Guedes, E., da Rocha Neto, J. and Glover, I. (2012). Development of a partial discharge emulator for calibration of a radiometric pd detection system, Instrumentation and $\mathrm{Mea}$ surement Technology Conference (I2MTC), 2012 IEEE International, pp. 2398 -2403.

Haykin, S. O. (1997). Neural Networks: a Comprehensive Foundation (International Edition), 2nd international edition. edn, Pearson.

IEC 60270 (2000). High-voltage test techniques - partial discharge measurements, Technical report, Geneve, Switzerland.

Nattrass, D. A. (1988). Partial discharge measurement and interpretation, IEEE Electrical Insulation Magazine 4(3): 10-23. DOI: $10.1109 / 57.830$

Tanaka, T. and Greenwood, A. (1983). Advanced power cable technology, Vol. Volume II, CRC press, Inc. 